DOI 10.1515/RJES -2016-0021

\title{
BOOK REVIEW: \\ PUNGĂ, LOREDANA (EDITOR). LANGUAGE IN USE: METAPHORS IN NON- LITERARY CONTEXTS, NEWCASTLE: CAMBRIDGE SCHOLARS PUBLISHING, 2016, 259 P.
}

\author{
SILVIA PASCU
}

Tibiscus University Timișoara

Metaphor has been extensively talked about so far. In time, the approaches have been various - within the area of humanities, they have ranged from purely linguistic, to cognitive, philosophical, stylistic, and sociological, to name just a few perspectives. Language in Use: Metaphors in Non-Literary Contexts, edited by Loredana Pungă and published by Cambridge Scholars in 2016, adds a number of points of view to the multitude of studies already dedicated to metaphor.

Born from the editor's declared belief "that there is always something more to say about metaphor" (2016: XV), the volume is a collection of sixteen articles relying, in their great majority, on Conceptual Metaphor theory. The contributions (mostly by Romanian scholars, but also by researchers from Hungary, Germany and Serbia) are grouped in two parts, preceded by a pretty lengthy Preface - a useful synopsis for anybody interested in a brief overview of the development of the matter under consideration. Here, the editor succinctly, yet relevantly, pinpoints the landmarks in the evolution of theories on metaphor, from the Antiquity thinkers Aristotle, Cicero, and Quintilian on to the $18^{\text {th }}$ century Romantic poets' view, Black's interaction view, Ortony's formulaic approach, Weinreich or Levin's componential analysis-based investigations, Searle's pragmatic ones, etc. to the late XXth century Conceptual Metaphor and blending theory. Part I. Metaphors at Play and Work comprises chapters focusing on metaphors employed either in everyday, non-specialized areas or in specific ones (sports, wine making and food and cooking), while Part II. Living with Metaphors brings together chapters on metaphors used in rather personal, intimate contexts (diary-writing and career interviews) as well as public ones (the classroom environment, the political arena, the advertising and the film industry, media campaigns).

Part I opens with Metaphors of/ in Translation, in which Eva Antal analyses the metaphors of truth, purity, integrity and fragmentation using Hans-Georg Gadamer's, Jacques Derrida's and Walter Benjamin's perspectives on translation as a starting point.

The next four chapters are comparative English - Serbian studies. Literal and Transferred Meanings of "Green" in English and Serbian: A Contrastive Analysis by Sonja Rodic brings the metaphorical meanings of the term green and of its corresponding Serbian equivalent - zelena into the limelight and suggests grouping them into three categories: similar meanings in both languages, partially overlapping meanings and meanings identified in only one of the two languages. The author shows that the literal meaning of green - zelena is illustrated by the first category, while the metaphorical meanings are specific to the latter 
two categories, the explanation for this distribution being found in the cultural difference between the two languages and, simultaneously, in the specificity of each of these.

In Metaphorical Ways of Expressing the Concepts "Good" and "Bad" in English and Serbian, Aleksandra Kardoš relies on prototype and Conceptual Metaphor theories and analyses various metaphorical linguistic embodiments of the concepts right and wrong, in English and Serbian. The conclusion the author arrives at is that adjectives carrying the positive connotation of "moral purity", "happiness", "intelligence", "sound clarity" co-exist with those at the opposite end of the "good-bad" spectrum - the ones that suggest "moral impurity", "sadness", "incomprehensibility" and "secrecy". The author considers collocations, idioms and free word combinations of which such adjectives are part and she compares and contrasts them in the two languages.

The Devil has no Shades of Grey: A Contrastive View of English and Serbian Metaphors for the Color "Black" by Sanja Krimer-Gaborovic discusses the black colourbased metaphors in English and Serbian. She argues that there are more similarities than differences between the two languages in how these metaphors convey either a positive or a negative meaning (though there is not always perfect linguistic equivalence between them), due, as she points out, to shared European ancestry of the languages concerned and more recently, to globalization, or rather overwhelming anglicization.

Mira Milić, in Metaphor in Sports Terminology in English and Serbian, places English and Serbian side by side from a different angle - that of sports terminology, as the title indicates (more exactly, that of ball games and gymnastics specialized vocabulary). Her main findings indicate that, in both languages, the metaphorical terms specific of ball games are usually based on the source domains of objects and war, while gymnastics metaphorical terminology draws more heavily on the domains of objects and animals. On the other hand, metaphorical association has proved to be slightly more productive in English than in Serbian, formal correspondence being quite high in the case of the war-related metaphorical terms in ball-games and the animal-related ones in gymnastics.

Daniela Gheltofan also takes a contrastive perspective on metaphors, this time the languages involved being Romanian and Russian and the domain considered - food and cooking. In her chapter - Food for Thought - Thought for Food: A Romanian-Russian Corpus of Metaphors Based on Culinary Terms, she focuses on the most frequent frames culinary metaphors build on and pays attention to the situations in which both the frames and their linguistic manifestations coincide in the two languages as well as to those in which they are different. Particular emphasis is placed on the cultural dimension of (some of) the phrases under scrutiny and on their humorous, ironic or even sarcastic connotations.

Loredana Pungă writes a chapter in a related area - that of wine tasting. In Anthropomorphic Metaphors in Wine Speak: A Conceptual and Context-Based Analysis, she proposes an interesting analysis of the anthropomorphic wine metaphors she identified in one hundred wine tasting notes produced in English. The approach is two-fold: on the one hand, the author analyses the metaphors along the now traditional lines of Conceptual Metaphor theory, on the other, she brings into discussion the role of contextual factors in the creation of these metaphors, building her arguments on the scaffolding represented by a theory very recently suggested by Kövecses.

Codruta Goșa's Metaphors in Diary Studies: A Glimpse “Inside the Black Box" paves the way for the other chapters in the second part of the volume. It is an analysis of the conceptual metaphors used by fourteen students in their diaries kept for a week, either on their reading or on their writing of their graduation papers. As the author demonstrates in her chapter, the study of diaries, along that of other genres, may play a role in shedding light on various aspects of metaphorical thinking. 
The Road of Life and the Ladder of Career: A Case Study of Romanian Life and Career Metaphors by Andreea Ioana Şerban highlights the conceptual metaphors used in the interviews taken of six Romanian women of different ages on their lives, education and careers. Particular prominence is given to the image schemas revealing the interviewees' choices in these respects, with the purpose of identifying variations in the subjects' attitudes and perceptions on the one hand, and of comparing these schemas (and their corresponding metaphors) with those identified by scholars and career specialists in English discourses.

Luminiţa Frențiu switches the focus to the public arena. In Politics-Words at War? A Metaphor Analysis of Presidential Election Speeches in Post-Communist Romania, she takes a close look at the conceptual metaphors employed by the Romanian presidential candidates during the 2014 campaign and compares them to those she talked about in an earlier study, focusing on the 2004 similar campaign, in an attempt to see whether changes occurred or the metaphorical conceptualization remained pretty much the same.

Another frequently tackled public domain is that of advertising. Annamaria Kilyeni dedicates her chapter - Body Matters: Metaphors of the Feminine Body in Print Advertisements to this domain, by choosing to describe the way metaphor is used to conceptualize women's body in advertising, in the particular case of three glossy magazines published in the United States and England. More attention is given to the anthropomorphising metaphors that picture the feminine body as if it were a socially active and sentient human being. Besides identifying and exemplifying these metaphors, the author speaks about their discursive role, insisting, at the same time, on that of promoting gender ideology.

In Metaphors and Calls for Action in Media Advocacy Campaigns on Social Issues, Irina Diana Mădroane brings Conceptual Metaphor theory close to the dialectical and rhetorical dimensions of argumentation in advocacy contexts. She echoes the Faircloughs' approach to political discourse as practical argumentation, in suggesting that metaphors are framing devices that may manipulate the audience's behaviour in taking particular decisions and supports this opinion with examples taken from a Romanian TV campaign geared on presenting the unacceptable circumstances the country's elderly live in. Implicitly, designed as it is, the campaign is also meant to suggest that the state is responsible for the disastrous and morally unacceptable situation and, consequently, to stir the public's indignation and move it into action.

Metaphors in Oral Classroom Discourse: The Case of the "Soc[k]" Dictionary by Valentina Carina Mureşan analyses the conceptual metaphors used by two teachers and their students, during eight English lessons, in the context of developing communicative and metaphoric competence in addition to the main, linguistic one.

The volume rounds off with three chapters dedicated to films. In the first Multimodal Metaphors in "The Romanian New Wave", Gabriela Tucan presents the way in which multi-modal, audio-visual metaphors are chosen by the directors to create sociocultural models which are well-known to the viewers, which they can therefore recognize and to which they are expected to react emotionally. The examples are selected from three "New Wave" Romanian productions.

In the second, Multimodal Metaphors in Films: "People are Animals" as a Gendered Conceptualization across Englishes, Anna Finzel discusses the gendered and, at the same time, culture-bound conceptualizations of the zoomorphic metaphor in four recent films produced in England, India and Nigeria. Details are provided on how this metaphor manifests linguistically, in images and sounds, in a context characterised by multimodality.

In the last chapter, Baking Layers of Meaning: The Grand Budapest Hotel (2014), Eliza Claudia Filimon constructs her analysis on Wittock's theory of rule disruption and 
highlights some multi-modal metaphorical elements used in the film indicated in the title and their role in engaging the audience in the meaning-making process.

As announced by the editor in the Preface, bringing together articles that propose different points of view on metaphor represents an insight into the intricacies of the human way of thinking. Conceptual Metaphor theory is not new in itself and there has been quite substantial research that has been done based on it. So, it is not in the approach that the novelty of this volume resides. It is rather in its potential of offering a kaleidoscopic view on the inexhaustible topic of metaphor (as the editor's declared intention was for it to do) and thus, of opening doors to further multi-faceted investigations in its area.

Well-conceived, this carefully-made selection of contributions to the study of metaphors may be of interest to a heterogeneous readership - descriptive, cognitive and comparative linguists, translators, teachers of foreign languages, politicians, advertisers or film makers. The accessible, yet professional language used turns it into a not very demanding reading experience for those who (however) possess knowledge of metaphor theory beyond the introductory level. 